\title{
Prevalence, Determinants and Impact of Haemoglobin Phenotype Misdiagnosis Among Parents of Children Living with Sickle Cell Disease in Nigeria
}

\author{
(1) Motunrayo Oluwabukola Adekunle1, (1) Oyesola Ojewunmi2, (1) Adeola Barakat Animasahun3, \\ ๑ Faith Ozavisa Lawani', ๑ Peter Odion Ubuane ${ }^{1}$ \\ 1'Lagos State University Teaching Hospital, Department of Paediatrics, Lagos, Nigeria \\ 2DNA Laboratory, Sickle Cell Foundation Nigeria, Lagos, Nigeria \\ ${ }^{3}$ Lagos State University College of Medicine, Department of Paediatrics and Child Health, Lagos, Nigeria
}

\begin{abstract}
Aim: Nigeria has the highest number of children with sickle cell disease (SCD) with a consistent prevalence of 2 to $3 \%$ despite increased awareness and widespread premarital screening. In our practice, we observed that complaints of haemoglobin phenotype misdiagnosis are common among parents of children living with SCD. The present study was thus carried out to identify the prevalence, determinants, as well as the perceived impacts of haemoglobin phenotype misdiagnosis in Lagos, Nigeria.

Materials and Methods: This study included the parents of children with SCD aged below 18 years. Interviewer administered questionnaires were used to obtain relevant biodata, sociodemographic data and an assessment of the perceived impact from both caregivers and their children, between May and July 2019.

Results: Fifty-nine (32.4\%) out of the 182 parents recruited had a previous haemoglobin phenotype misdiagnosis. Misdiagnosis was significantly more in individuals in the upper social class and those that had their tests performed in private laboratories. Clinical, psychosocial and economic impacts of having an affected child with SCD were reported.

Conclusion: The frequency of wrong haemoglobin phenotype diagnosis is alarmingly rampant amongst the parents of children with SCD. This is potentially devastating to these families and to society; hence, the government needs to act by auditing and enforcing regulatory oversight of laboratories as well as instituting a nationwide new-born screening programme to replace the existing widespread use of haemoglobin electrophoresis for the diagnosis of SCD.
\end{abstract}

Keywords: Misdiagnosis, haemoglobin-phenotype, sickle cell disease, laboratory, Nigeria 


\section{Introduction}

Nigeria has the highest number of persons with the sickle cell trait and sickle cell disease (SCD) in the world (1). Yearly, about 150,000 babies are born with SCD while a quarter of Nigerians carry the sickle cell trait (1). SCD can be prevented by the early identification of carriers, genetic counselling and prenatal diagnosis (2).

A noteworthy but unfortunate factor that is contributing to the public health burden of this disorder in Nigeria is the wrong diagnosis of haemoglobin phenotypes (3). In practise, we have encountered many partners that married on the basis of compatible haemoglobin phenotypes only to be faced later with the shocking reality of both being sickle cell carriers after the birth of a child discovered to have SCD during protracted or recurrent illnesses, or even after debilitating complications like cerebrovascular accident. Such incidents have resulted in broken homes or marital distrust out of the misconception that one partner was dishonest about their haemoglobin phenotype status.

Alkaline haemoglobin electrophoresis is currently the most widely used method of haemoglobin phenotype testing in Nigeria and is the sole technique used by most laboratories despite its limitations (4). Aside from being the only method of diagnosis, inappropriate practices such as the use of inferior cellulose acetate electrophoresis paper and machine and also the absence of control samples may account for these misdiagnoses. The standard recommended practice, however, is to perform sickling/solubility test alongside alkaline haemoglobin electrophoresis in order to confirm samples with $\mathrm{Hb} \mathrm{S}$ and ultimately to rule out the presence of haemoglobins $G$ and D which could be found in our population and usually co-migrate with $\mathrm{Hb} \mathrm{S}$ in alkaline electrophoresis $(5,6)$. The routine use of HPLC, the goldstandard diagnostic modality, is rare in Nigeria.

Although public sensitization programmes have considerably increased the populace's awareness of sickle cell disorders, as well as the utility of screening procedures such as premarital haemoglobin phenotype testing, the expected consequent reduction in the prevalence of SCD, especially in children, is yet to be seen (7-10).

Therefore, this study investigated the burden, determinants and impact of misdiagnoses of haemoglobin phenotypes so that this knowledge may guide specific interventions that could curb or mitigate the role of misdiagnosis in the persistently high endemicity of SCD in Nigeria.

\section{Research Questions}

1. What proportion of parents of children (below 18 years) with SCD had haemoglobin phenotype testing premaritally?

2. How many parents knew their haemoglobin phenotype results before the birth of any of their children with sickle cell disorder?

3. How many parents of children with SCD had at least one previously wrong genotype diagnosis?

4. What are the factors associated with wrong genotype diagnosis (place of testing, number of times testing was done, socio-economic class of the primary caregiver)?

5. What was the perceived impact of the misdiagnosis of sickle cell disorder on the child, couple and family?

\section{Aim and Objectives}

General Aim: To determine the prevalence, determinants and impact of wrong haemoglobin genotype results among the parents of children living with sickle cell disorders.

\section{Specific Objectives}

1. To determine the prevalence of wrong haemoglobin genotype results among the parents of children living with sickle cell disorders.

2. To determine the determinants of wrong haemoglobin genotype results among the parents of children living with sickle cell disorders.

3. To determine the impact of wrong haemoglobin genotype results among the parents of children living with sickle cell disorders.

\section{Materials and Methods}

\section{Study Design}

The current study was a cross sectional, questionnairebased and qualitative study, involving the parents of children with sickle cell disorder that attended the Sickle Cell Foundation, Idi-Araba, Lagos State, Nigeria between May and July 2019. The Sickle Cell Foundation is a nongovernmental organization that provides services such as genetic screening, medical care, research, counselling and training related to sickle cell disorder. It receives individuals with sickle cell disorder from Lagos state and its neighbouring states due to its highly subsidized and expert care.

\section{Study Setting, Population and Recruitment}

An unknown prevalence of 50\% was used in determining the sample size in the current study (11). Subjects who met 
the inclusion criteria were subsequently recruited until the desired sample size was met.

Government hospitals, also called public hospitals, were defined as hospitals established and funded by the government (12).

The inclusion criteria were parents of children who had previously been diagnosed with SCD by electrophoresis and who agreed to participate in the study. These parents were recruited until the desired sample size was reached.

Those excluded from the study were parents of subjects with unknown haemoglobin phenotype, parents with no knowledge of when/where their genotype test was done and caregivers other than the biological parents.

\section{Ethical Approval}

Approval for this study was obtained from the Health Research Ethics Committee of Lagos State University Teaching Hospital (NHREC04/04/2008) and all the participants gave written informed consent while those children aged seven years and above gave their assent.

\section{Data Collection Method}

A self-designed questionnaire was used to obtain information from the study participants. The biodata and questions about time of diagnosis, place of diagnosis, and any previous wrong diagnosis in either or both parents were obtained. The impact of having a child or children with SCD on the family (parents and children) was ascertained using a previously created tool by Brown et al. (13).

\section{Statistical Analysis}

The data were analysed using Statistical Package for Social Sciences (SPSS) version 20.0. Descriptive statistics were presented as medians with interquartile range for skewed data. Continuous variables were compared between two groups using the student's t-test, categorical variables were compared between two or more groups. Statistical significance was set at $\mathrm{p}$-value $<0.05$.

\section{Results}

A total of 190 parents and child sets were recruited, out of which 8 were excluded (4 cases of unknown genotype of parents, 2 cases of relatives as primary caregivers and 2 cases of previous recruitment of siblings). The majority of the study children were homozygous for SCD - Hb SS ( $n=178,97.8 \%$ )- and 4 (2.2\%) were compound heterozygous HbSC. Thus, a total of 182 children aged 6 months to 204 months with SCD and their parents' responses were analysed. The median age of children with SCD was 84 months [interquartile range $(I Q R)=60-123$ ]; boys and girls had similar ages at 84 months $(I Q R=60-132)$ vs. 96 months (IQR=48-120), $z=-0.494, p=0.621)$. A total of $103(56.6 \%)$ of the children with SCD were males with a male-to-female ratio of 1.6:1.

As shown in Table I, about $80 \%$ of the children with SCD were less than 10 years of age and about $90 \%$ had both biological parents as primary caregiver. The majority of the mothers and fathers were in the third and fourth decade of life, respectively. About one-third of the children were from upper-income, one-third from middle-income and onethird from lower-income families.

There is significant association between the time of testing and social class. A larger proportion of those parents in the upper social class had haemoglobin phenotype tests done before marriage compared to those in the middle and lower social classes as shown in Table II.

The majority of the parents (father-mother pairs) were of AS-AS phenotypes (Figure 1). Only 9 (4.9\%) couples had other sickle cell traits or homozygous sickle cell anaemia in one member.

\begin{tabular}{|l|l|l|}
\hline \multicolumn{2}{|l|}{ Table I. Socio-demographic characteristics of subjects } \\
\hline Age group & Frequency & Percentages \\
\hline$\leq 5$ years & 60 & 33.0 \\
6 -10 years & 77 & 42.3 \\
11-18 years & 45 & 24.7 \\
\hline Mothers' age groups & Number of subjects & Percentages \\
\hline$<20$ & 1 & 0.5 \\
$20-29$ & 19 & 10.4 \\
$30-39$ & 101 & 55.5 \\
$40-49$ & 59 & 32.4 \\
$\geq 50$ & 1 & 0.5 \\
Unknown & 1 & 0.5 \\
\hline Fathers' age groups & Number of subjects & Percentages \\
\hline $20-29$ & 2 & 1.1 \\
30-39 & 44 & 22.9 \\
40-49 & 109 & 56.8 \\
$\geq 50$ & 34 & 17.7 \\
Unknown & 3 & 1.6 \\
\hline Marital status of & Frequency & Percentages \\
caregivers & 3 & 1.6 \\
Single & 10 & 5.5 \\
Separated/divorced & 162 & 89.0 \\
Married & 7 & 3.8 \\
Widowed & Frequency & Percentages \\
\hline SEC & 57 & 31.3 \\
Upper & 63 & 34.6 \\
Middle & 62 & 34.1 \\
Lower & & \\
\hline SEC: Socio-economic class & & \\
\hline
\end{tabular}


Table II. Relationship between time of testing and social classes

\begin{tabular}{|c|c|c|c|c|}
\hline Time of testing & Upper (\%) & Middle (\%) & Lower (\%) & p-value \\
\hline Before marriage & $53(93.0)$ & $45(71.4)$ & $43(69.4)$ & \multirow{3}{*}{$\begin{array}{l}\chi 2=11.516 \\
p=0.003^{*}\end{array}$} \\
\hline After marriage & $4(7.0)$ & $18(28.6)$ & $19(30.6)$ & \\
\hline Total & $57(100.0)$ & $63(100.0)$ & $62(100.0)$ & \\
\hline \multicolumn{5}{|c|}{ Parental knowledge of genotype after child's diagnosis } \\
\hline No & $40(70.2)$ & $35(55.5)$ & $30(48.4)$ & $\chi^{2}=5.956$ \\
\hline Yes & $17(29.8)$ & $28(44.4)$ & $32(51.6)$ & $p=0.05$ \\
\hline Total & $57(100.0)$ & $63(100.0)$ & $62(100.0)$ & \\
\hline
\end{tabular}

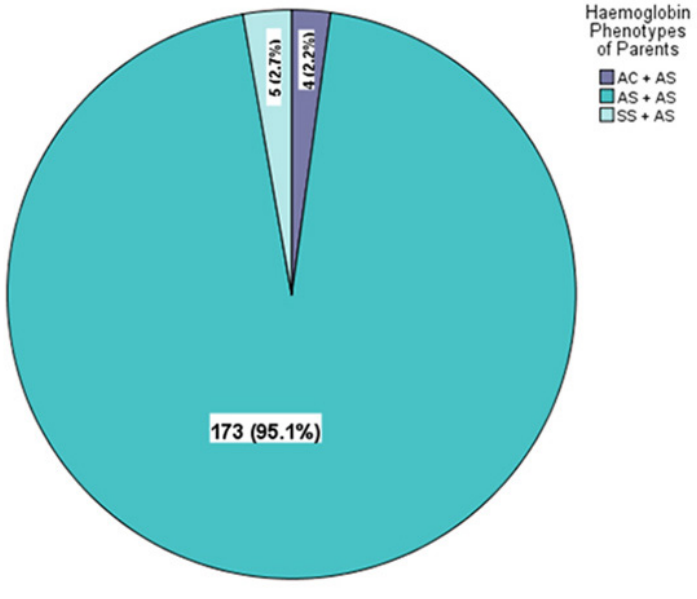

Figure 1. Haemoglobin phenotypes of the parents

\section{Frequency of Wrong Haemoglobin Phenotyping}

Almost one-third ( $n=59 / 182,32.4 \%)$ of either parent had been previously mistyped as $\mathrm{HbAA}$ (Figure 2). Three of the four mothers with $\mathrm{HbAC}$ had been previously misdiagnosed as HbAA.

\section{Factors Associated With Misdiagnosis}

Those parents who had had multiple haemoglobin phenotype tests done had a lower occurrence of misdiagnosis compared to those who had done the test only once [37 $(62.7 \%)$ vs $\left.22(37.3 \%) ; \chi^{2}=49,860, p=0.0001\right]$.

In all, 62 (34.1\%) and 63 (34.6\%) parents are in the lower and middle social class respectively. Individuals in the upper social class had a significantly higher proportion of misdiagnosis compared to those in the middle and lower social classes $[26(44.1 \%)$ vs $23(39.0 \%)$ vs 10 (16.9\%); $\left.\chi^{2}=12,520, p=0.002\right]$.

A significant proportion of parents who had haemoglobin phenotype misdiagnosis had the investigation done at various private laboratories and private hospitals compared to those done in government hospitals as shown in Table III.

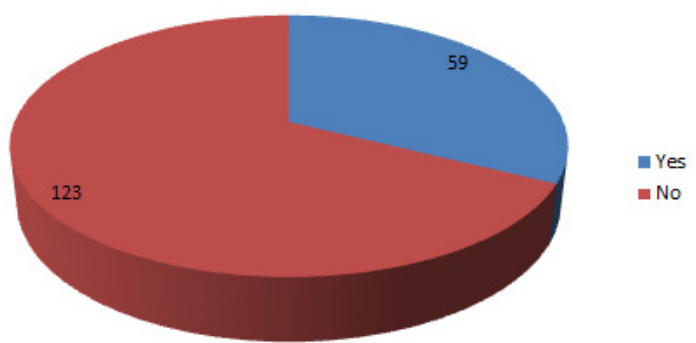

Figure 2. Frequency of haemoglobin phenotype misdiagnosis

\section{Perceived Impacts of Misdiagnosis}

Among the caregivers with a previous misdiagnosis of haemoglobin phenotype, about two-thirds ( $n=44 / 59$, $74.6 \% ;)$, one-fifth $(n=13 / 59,22.0 \%)$ and less than a tenth $(n=2 / 59,3.4 \%)$ had one, two and three children with $S C D$, respectively. Figure 3 lists the various clinical and psychosocial impacts of having a child with SCD identified in subjects with previous wrong genotype testing.

\section{Discussion}

As high as $42.3 \%$ of the parents in the present study realised they had a sickle cell trait after the birth of an affected child. This is similar to previous report by Ezenwosu et al. (14) in the South-Eastern part of Nigeria. A new-born screening programme for SCD is currently not available in Nigeria and very few health facilities have the highly specific diagnostic methods such as high-performance liquid chromatography (HPLC), which is very expensive. Haemoglobin electrophoresis machines are relatively cheaper, widely available in many centres and thus remain the most commonly used method for the diagnosis of SCD in Nigeria (14). In the last few decades, Nigeria has witnessed increased awareness of primary prevention of SCD among its populace such that premarital haemoglobin 
Table III. Relationship of genotype test results to the place of testing

\begin{tabular}{|l|l|l|l|}
\hline \multicolumn{5}{|l|}{ Previous wrong haemoglobin genotype testing } \\
\hline Place of testing & No (\%) & Yes (\%) & Total (\%) \\
\hline Government hospitals & $45(83.3)$ & $9(16.7)$ & $54(100)$ \\
\hline Private hospitals & $42(66.7)$ & $21(33.3)$ & $63(100)$ \\
\hline Private laboratories & $36(55.4)$ & $29(44.6)$ & $65(100)$ \\
\hline Total & $123(67.6)$ & $59(32.4)$ & $182(100)$ \\
\hline$\chi 2=10,553, p=0.005$ & & \\
\hline
\end{tabular}

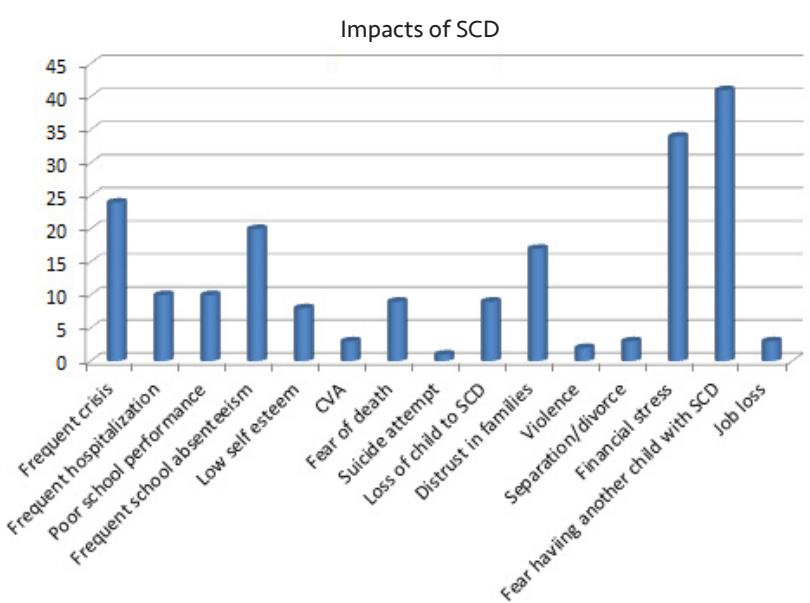

Figure 3. Impact of SCD on the affected child and caregivers in misdiagnosed caregivers

SCD: Sickle cell disease, CVA: Cerebrovascular accident

phenotyping is currently encouraged and practised by the many major religious groups in Nigeria as a measure to forestall births of children with SCD through informed marital decisions. Unfortunately, however, misdiagnosis is still highly prevalent as observed in our study; a large number of the parents we sampled married on the premise on the premise of compactible haemoglobin phenotype with no risk of having a child with HbSS.

Persons in the high social class had more phenotype testing done before marriage/child birth compared to individuals in the lower social classes in our cohort. There has been an increased dissemination of information in schools on SCD and the need for testing in recent times and this could have contributed to the awareness and earlier screening in persons in the high social class.

Three out of four parents with the HbAC phenotype in the current study were previously diagnosed as HbAA, and almost a third of participants had been wrongly diagnosed in the past. There are many sources of error in haemoglobin phenotype diagnosis as it is currently done in most diagnostic centres in Nigeria. Some could include the non-use of positive control samples ( $A S$ and $A C$ ), the use of inferior electrophoresis set-up and low-quality cellulose acetate paper, the re-cycling of acetate papers in order to cut cost as well as the use of unqualified personnel in the conduct of haemoglobin phenotyping (15).

In the present study, we observed that a significantly higher proportion of misdiagnosis occurred in private laboratories compared to government or private hospitals. An even more disturbing finding was that misdiagnosis was still high in subjects who had testing done more than once. Perhaps this suggests that poor quality results are widely prevalent. Mitigating these dangerous practices requires that the relevant agencies guiding the medical laboratory practice in Nigeria ensure strict monitoring and compliance of these laboratories in order to reach the recommended standard operating procedures. The Medical Laboratory Science Council of Nigeria regulates, inspects and accredits medical laboratories in Nigeria (16). However, "quack" laboratory scientists are rampant in our environment and the use of non-accredited, and hence unregulated, private laboratories by some citizens may account for this high frequency of misdiagnosis. In addition to curb this menace, the populace needs more education on the existence and potential dangers of such laboratories as well as the means of identifying adequately accredited ones.

Our finding suggests that errors in the diagnosis of the haemoglobin phenotype is less prevalent in public-owned compared to private laboratories. This may be a reflection of the comparatively higher statutory regulatory oversight in government-owned facilities. However, long waitingtimes may discourage the use of public-owned laboratories despite being relatively cheaper than the private ones. Perhaps, this may explain why a larger proportion of those of higher social class had more misdiagnoses than those of lower status since they may be able to afford the private services with shorter waiting-times.

The standard practice of haemoglobin phenotype determination should also include a qualitative test widely known as sickling or solubility test, which helps to provide additional information that may not be available in the alkaline haemoglobin electrophoresis method. For instance, Haemoglobins S, D, and G migrate together in the same lane in alkaline electrophoresis. As a result, $\mathrm{Hb}$ D or $\mathrm{G}$ in a heterozygous individual will appear as $\mathrm{Hb} \mathrm{S}$; but in the sickling/solubility test, only $\mathrm{Hb} \mathrm{S}$ forms precipitate showing a positive sickling/solubility test, while $\mathrm{Hb} \mathrm{D}$ and $\mathrm{G}$ remain soluble, indicating a negative sickling/solubility test $(5,6)$. 
The use of hemolysate, instead of whole blood, for electrophoresis should be encouraged to ensure a more accurate diagnosis since other possible interfering proteins would have been washed off during hemolysate preparation. It is important to note that where appropriate diagnosis cannot be made with the use of both alkaline electrophoresis and sickling/solubility test, wrong assumptions must be avoided. Such blood samples should be sent to a better equipped laboratory that can offer definitive haemoglobin phenotype diagnosis. In such cases, a complete blood count, HPLC, and acid electrophoresis might provide some useful hints in cases of the presence of unusual haemoglobin variants.

However, the most effective lasting and long-term solution to the problem of haemoglobin diagnosis is to institute a nationwide new-born screening programme to replace the existing widespread use of haemoglobin electrophoresis with the more sensitive HPLC which gives a more accurate result as well as the early identification of carriers and infants with SCD.

The clinical and psychosocial impacts of having at least one child with SCD were identified in parents with wrong diagnosis in the current study. Parental fear of having another "sick" child, the financial stress and frequent crises of affected children were the most commonly reported effects. Some individual responses are given below:

A respondent: I was very angry when I realized my son has sickle cell anaemia and I went to that private laboratory to fight. My wife knew she is HbAS and I went to this lab before marriage and was given a result of HbAA. I realised I am HbAS after re-testing following my son's (who is the second and last child) frequent ill health that led to his diagnosis. There has been a lot of pressure from my parents for us to have more children but I cannot handle another child with SCD.

Another respondent: We realized my son has sickle cell anaemia after he had a stroke. I told the doctor this was not possible. I am educated and I did my test in a government hospital which was AA. The doctor advised me to repeat it and I got another result of AS. Currently my son is yet to speak, he is on physiotherapy and the financial implication is huge.

In Nigeria, where an out-of-pocket financing system is still mostly practiced, the financial burden of SCD on families is enormous, as was previously reported by Olatunya et al. (17). The marked effect of SCD on families in our environment is significant and having these effects following a misdiagnosis is quite disturbing and devastating to a family, especially in a society where family ills may be readily attributed to the woman's fault. This further emphasises the need to ensure compliance with standards in phenotype diagnoses and the institution of effective measures to curb laboratory practices by unqualified or incompetent doctors.

\section{Conclusion}

In conclusion, the misdiagnosis of the haemoglobin phenotype is rampant in our environment, especially in private laboratories. There is a need for effective and prompt measures to curtail this menace. More importantly, the need for effective nationwide new-born screening for SCD cannot be overemphasized.

\section{Ethics}

Ethics Committee Approval: Approval for this proposed study was obtained from the Health Research Ethics Committee of Lagos State University Teaching Hospital (NHREC04/04/2008).

Informed Consent: All the participants gave written informed consent while the children from seven years and above gave their assent.

Peer-review: Externally peer-reviewed.

\section{Authorship Contributions}

Concept: M.O.A., P.O.U., Design: M.O.A., P.O.U., Analysis or Interpretation: M.O.A., P.O.U., Literature Search: M.O.A., P.O.U., Writing: M.O.A., O.O., A.A., P.O.U., F.L.

Conflict of Interest: No conflict of interest was declared by the authors.

Financial Disclosure: The authors declared that this study received no financial support.

\section{References}

1. Akinyanju OO. A profile of sickle cell disease in Nigeria. Ann NY Acad Sci 1989; 565:126-36.

2. Traeger-Synodinos I, Vrettou C, Kanavakis E. Rapid detection of fetal Mendelian disorders: thalassemia and sickle cell syndromes. Methods Mol Biol 2008; 444:133-45

3. How Wrong Genotype Diagnosis Contributes To SCD in Nigeria - Don. The Precision.com. Accessed January, 2020. https:// theprecisionng.com/2020/01/wrong-genotype-diagnosiscontributes-scd-nigeria-d.html

4. Obaro SK, Daniel Y, Lawson JO, et al. Sickle-Cell Disease in Nigerian Children: Parental Knowledge and Laboratory Results. Public Health Genomics 2016; 19:102-7.

5. Kotila TR. Guidelines for the diagnosis of the haemoglobinopathies in Nigeria. Ann Ib Postgrad Med 2010; 8:25-9. 
6. Adeyemo T, Ojewunmi O, Oyetunji A. Evaluation of high performance liquid chromatography (HPLC) pattern and prevalence of beta-thalassaemia trait among sickle cell disease patients in Lagos, Nigeria. Pan Afr Med J 2014; 18:71.

7. Adewoyin AS, Alagbe AE, Adedokun BO, Idubor NT. Knowledge, attitude and control practices of sickle cell disease among youth corps members in Benin city, Nigeria. Ann lb Postgrad Med2015; 13:100-7

8. Uche E, Olowoselu O, Augustine B, et al. An assessment of knowledge, awareness and attitude of undergraduates toward sickle cell disease in Lagos, Nigeria. Niger Med J.2017; 58:167-72

9. Fleming AF, Storey J, Molineaux L, Iroko EA, Attai ED. Abnormal haemoglobins in the Sudan savannah of Nigeria: I. Prevalence of haemoglobins and relationships between sickle cell trait, malaria and survival. Annals of Trop Med Parasitol 1979; 73:16172

10. Jiya NM, Umar A, Ibrahim KK, et al. Sickle cell anaemia: A prevalence study among the children attending Usmanu Danfodiyo University Teaching Hospital, Sokoto, North-Western Nigeria. Asian / Med Health 2017; 2:1-8

11. Daniel WW. Biostatistics: a foundation for analysis in the health sciences. 7th ed. New York: John Wiley \& Sons; 1999.
12. Essays UK. (November 2018). Government and private hospital differences health and social care essay. Available from: https://www.ukessays.com/essyas/health-and-social-care/ government-and -private-hospital-differences-health-andsocial-care-essay.php?

13. Brown BJ, Okereke JO, Lagunju IA, Orimadegun AE, Ohaeri JU, Akinyinka OO. Burden of health-care of carers of children with sickle cell disease in Nigeria. Health Soc Care Community 2010; 18:289-95.

14. Ezenwosu OU, Chukwu BF, Ikefuna AN, et al. Knowledge and awareness of personal sickle cell genotype among parents of children with sickle cell disease in southeast Nigeria. । Community Genet 2015; 6:369-74

15. Ojewunmi OO, Adeyemo TA, Ayinde OC, Iwalokun B, Adekile A. Current perspectives of sickle cell disease in Nigeria: changing the narratives. Expert Rev Hematol 2019; 12:609-20.

16. Medical Laboratory Science Council of Nigeria. Quality Manual. Last Accessed Date: 05.11.2019. Available from: www.mlscn. gov.ng.

17. Olatunya OS, Ogundare EO, Fadare JO, et al. The financial burden of sickle cell disease on households in Ekiti, Southwest Nigeria. Clinicoecon Outcomes Res 2015; 7:545-53. 